\title{
Role of Dual Energy Contrast Enhanced Mammography in Characterization of Lesions in Edematous Breast
}

\author{
BASMA A. HASSANIN, M.Sc.; SHERINE K. AMIN, M.D. and RASHA S. HUSSEIN, M.D. \\ The Department of Radio-diagnosis and Nuclear Medicine, Faculty of Medicine, Ain Shams University
}

\begin{abstract}
Background: Breast edema can be caused by benign or malignant diseases. Initial mammography and breast ultrasound examination are the routine investigative modalities. Sometimes, mammography and ultrasonography can't characterize lesions especially in edematous breast. Contrast-enhanced digital mammography is a new breast imaging technique that can help in characterization of equivocal lesions.

Aim of Study: The purpose of this study is to assess the role of dual energy contrast enhanced digital mammography in detection, evaluation and characterization of breast lesions in edematous breasts.

Patients and Methods: This study was a cross sectional prospective study conducted at Ain-Shams University Hospitals at department of radiology and private radiology centers on 20 cases with breast oedema. No age predilection. Patients with previous surgery were included.
\end{abstract}

Results: There were 12 patients $(60 \%)$ with mass and 5 patients $(25 \%)$ with history of previous surgery. Pathological lymph nodes were detected in 11 patients $(55 \%)$, bilateral in one patient $(9.1 \%)$, left sided in 5 patients $(45.5 \%)$ and right sided in 5 patients $(45.5 \%)$. As regard conventional mammography, 19 patients $(95 \%)$ were positive for edema, while 11 patients $(55 \%)$ were positive for a mass (irregular, central) and one patient $(5 \%)$ was positive for calcifications. Regarding histopathology, there were 6 patients $(30 \%)$ diagnosed with benign condition and 14 patients $(70 \%)$ diagnosed with malignant tumors. The 14 patients with malignant tumors, $92.9 \%$ out of them were true positive of contrast enhanced digital mammography and $7.1 \%$ were false negative. There were 6 patients histopathologically proved to be benign tumor and $83.3 \%$ out of them were true negative and $16.7 \%$ were false positive on contrast enhanced digital mammography. There was statistically significant agreement between histopathology and contrast enhanced digital mammography a yielded Kappa value of 0.762 and $p$-value $<0.05$.

Conclusion: The addition of dual energy contrast enhanced digital mammography technique can significantly improve the detection of underlying breast lesions in edematous breasts.

Key Words: Breast edema - Contrast enhanced digital mammography - Sono-mammography.

Correspondence to: Dr. Basma A. Hassanien, E-Mail: bosybosy2013@yahoo.com

\section{Introduction}

BREAST cancer is the most common type of cancers being diagnosed in women and the most common cause of death from cancer in women [1]

Edema of the breast can be resulted from multiple pathological processes either from benign or malignant diseases. It may occur with local causes such as inflammatory breast carcinoma, mastitis, lymphatic obstruction, lymphoma or post radiational changes. Also, it may occur with systemic condition like congestive heart failure, nephritic and nephrotic syndromes of the kidney [2] .

Examination of the breast with initial digital mammography and ultrasound are the routine investigations for breast lesions. In mammography, edema can be diagnosed with thickening of the skin, increased parenchymal density and prominent interstitial markings. On the other hand, ultrasound edema pattern diagnosed by marked increase in the skin thickening, increased subcutaneous fat echogenicity with dilated lymphatics that appears as reticular anechoic structure. But both modalities findings still non specific for diagnosis [3].

Recently, we can have the advantage of digital mammography and other advanced screening applications to get more clinical benefits and save costs to improve standard of health care. Contrast enhanced digital mammography (CEDM), can easily detect tumor angiogenesis also has apriority for malignancy detection when compared with conventional mammography alone. CEDM is a promising diagnostic tool in breast imaging [4] .

\section{Aim of the work:}

The purpose of this study is to assess the role of dual energy contrast enhanced digital mammography in detection, evaluation, and characterization of breast lesions in edematous breasts. 


\section{Patients and Methods}

This study was a cross sectional prospective study, carried out on females ranging from 34 to 65 years, (mean age of $45.5 \pm 7.49$ years).

Started from March 2019 to March 2021 at Ain-Shams University Hospitals, Department of Radiology and private radiology centres. The study was conducted on 20 female with breast oedema. We included any women presenting with breast edema on conventional imaging (ultrasonography or mammography). We excluded patients with renal insufficiency, pregnant females, patient with a known history of allergy or previous reaction to contrast media or in severe pain. Participants were fully informed about the procedures and gave their consent to participate. The study was performed after approval of the Ethical Committee of Scientific Research, Faculty of Medicine, Ain Shams University.

\section{Study tools and procedures:}

Both conventional and contrast enhanced digital mammography examinations were done using GE Senographe 2000D full-field digital mammography system from GE Healthcare; Chalfont St-Giles, UK. It used a current full-field digital mammography system using a flat panel detector with CsI absorber, field size 19x23, del pitch of $100 \mathrm{~mm}$, image matrix size 1,914x2,294 (Senographe2000D) with certain specific software and hardware adaptations for acquisition and image processing.

\section{1- Dual Energy Contrast Enhanced Digital} Mammography was done as follow: Catheter was inserted into the antecubital vein of the arm contralateral to the breast of concern. A one-shot intravenous injection of non-ionic contrast agent (Omnipaque 350, Guerbet France) was administered manually at a dose of $1.5 \mathrm{ml} / \mathrm{kg}$ body weight.

A pair of low- and high-energy exposures was performed $2 \mathrm{~min}$ after the initiation of contrast agent administration. The breast was compressed in a $\mathrm{CC}$ position of the normal breast then another $\mathrm{CC}$ view and MLO view of the breast of concern. Then last view of other breast in MLO position.

Then a combination of low-energy and highenergy images through a specific image processing unit were performed to generate two subtracted images with contrast agent uptake information (MLO view and CC view).

2- Ultrasound study: All patients were examined by ultrasound using ultrasound device of GE Healthcare (LOGIQ E9 with XD clear premium ultrasound).

\section{Results}

We conducted our study on 20 patients with edematous breast. The study was conducted on a wide age group ranging from 34 to 65 years, (mean age of $45.5 \pm 7.49$ years).

Table (1): Association between Conventional mammography considering "mass as positive results" compared to Histopathology "Gold standard" according to characterization of lesions in edematous breast.

\begin{tabular}{lccccccc}
\hline & \multicolumn{3}{c}{ Histopathology } & \multirow{2}{*}{ Total } \\
\cline { 2 - 6 } $\begin{array}{l}\text { Conventional } \\
\text { mammography }\end{array}$ & \multicolumn{2}{c}{ Malignant } & \multicolumn{2}{c}{ Benign } & & \\
\cline { 2 - 6 } & No. & $\%$ & No. & $\%$ & No. & $\%$ \\
\hline Positive & 10 & 71.4 & 1 & 16.7 & 11 & 55.0 \\
Negative & 4 & 28.6 & 5 & 83.3 & 9 & 45.0 \\
& 14 & 100.0 & 6 & 100.0 & 20 & 100.0 \\
\hline Total & & & & & &
\end{tabular}

The table shows that there were 14 patients with malignant tumors on histopathology, $71.4 \%$ out of them were true positive on conventional mammography and $28.6 \%$ were false negative on conventional mammography. While there were 6 patients with benign tumor on histopathology and $83.3 \%$ out of them were true negative on conventional mammography and $16.7 \%$ were false positive on conventional mammography. There was significant agreement between histopathology and conventional mammography with Kappa value of 0.479 the indicate to moderate agreement and $p$ value $<0.05$.

Table (2): Comparison between conventional mammography finding a mass as a positive result and histopathology diagnosing a mass in edematous breast.

\begin{tabular}{llc}
\hline False diagnosis & Pathologic diagnosis & No. of cases \\
\hline False Negative & & $4(28.6 \%)$ \\
& $\begin{array}{l}\text { Recurrent IDC } \\
\text { Mixed invasive ductal \& } \\
\text { invasive lobular carcinoma }\end{array}$ & 2 \\
& $\begin{array}{l}\text { IDC } \\
\text { False Positive }\end{array}$ & 1 \\
& $\begin{array}{c}\text { Non caseating granulomatous } \\
\text { mastitis }\end{array}$ & $1(16.7 \%)$ \\
& & 1 \\
\hline
\end{tabular}

Four patients (28.6\%) were false negative, and 1 patient out of them recurrent IDC; two patients mixed invasive ductal \& invasive lobular carcinoma and 1 patients IDC. There was one patient $(16.7 \%)$ with false positive that is non caseating granulomatous mastitis (Fig. 1). 
Table (3): Shows analysis of True Positive, Negative and Positive and Negative Predictive value entities with Conventional mammography considering "mass as positive results" compared to Histopathology "Gold standard" according to characterization of lesions in edematous breast.

\begin{tabular}{lc}
\hline Diagnostic performance & Outcome\% \\
\hline Sensitivity & $71.4 \%$ \\
Specificity & $83.3 \%$ \\
Positive Predictive value & $90.9 \%$ \\
Negative Predictive value & $55.6 \%$ \\
Accuracy & $75.0 \%$ \\
\hline
\end{tabular}

As regard Conventional mammography, the evaluation of diagnostic performance showed Sensitivity (71.4\%), Specificity (83.3\%), Positive Predictive value (90.9\%), Negative Predictive value (55.6\%) and Accuracy (75\%).

Table (4): Association between Contrast Enhanced Digital Mammography considering "Enhancement as positive results" compared to Histopathology "Gold standard" according to characterization of lesions in edematous breast.

\begin{tabular}{|c|c|c|c|c|c|c|}
\hline \multirow{3}{*}{$\begin{array}{l}\text { Contrast } \\
\text { enhanced } \\
\text { digital } \\
\text { mammography }\end{array}$} & \multicolumn{4}{|c|}{ Histopathology } & \multirow{2}{*}{\multicolumn{2}{|c|}{ Total }} \\
\hline & \multicolumn{2}{|c|}{ Malignant } & \multicolumn{2}{|c|}{ Benign } & & \\
\hline & No. & $\%$ & No. & $\%$ & No. & $\%$ \\
\hline Positive & 13 & 92.9 & 1 & 16.7 & 14 & 70.0 \\
\hline Negative & 1 & 7.1 & 5 & 83.3 & 6 & 30.0 \\
\hline Total & 14 & 100.0 & 6 & 100.0 & 20 & 100.0 \\
\hline
\end{tabular}

Fourteen patients with malignant tumors on histopathology, $92.9 \%$ out of them were true positive on contrast enhanced digital mammography (Fig. 2) and $7.1 \%$ was false negative on contrast enhanced digital mammography. While there were 6 patients with benign tumor on histopathology and $83.3 \%$ out of them were true negative on contrast enhanced digital mammography and $16.7 \%$ was false positive on contrast enhanced digital mammography (Fig. 1). There was statistical significant agreement between histopathology and contrast enhanced digital mammography a yielded weighted Kappa value of 0.762 the indicate to substantial agreement and $p$-value $<0.05$.

Table (5): Contrast Enhanced Digital Mammography considering "Enhancement as positive results" compared to Histopathology "Gold standard" according to characterization of lesions in edematous breast.

\begin{tabular}{lc}
\hline Diagnostic performance & Outcome\% \\
\hline Sensitivity & $92.9 \%$ \\
Specificity & $83.3 \%$ \\
Positive Predictive value & $92.9 \%$ \\
Negative Predictive value & $83.3 \%$ \\
Accuracy & $90.0 \%$ \\
\hline
\end{tabular}

The evaluation of diagnostic performance for contrast enhanced digital mammography showed Sensitivity $(92.9 \%)$, Specificity $(83.3 \%)$, Positive Predictive value (92.9\%), Negative Predictive value $(83.3 \%)$ and Accuracy (90\%).

Table (6): Comparison between CEDM found positive enhancement with histopathology found a lesion in edematous breast.

\begin{tabular}{llc}
\hline False diagnosis & Pathologic diagnosis & No. of cases \\
\hline False Negative & IDC & $1(7.1 \%)$ \\
False Positive & Non caseating & $1(16.7 \%)$ \\
& granulomatous mastitis & \\
\hline
\end{tabular}

One patient $(7.1 \%)$ was false negative that was IDC, and one patient (16.7\%) was false positive that was non caseating granulomatous mastitis (Fig. 1).

Table (7): Association between Ultrasound considering "Pathological lymph nodes as positive results" compared to Histopathology "Gold standard" according to characterization of lesions in edematous breast.

\begin{tabular}{lccccccc}
\hline & \multicolumn{4}{c}{ Histopathology } & \multirow{2}{*}{ Total } \\
\cline { 2 - 6 } Ultrasound & \multicolumn{2}{c}{ Malignant } & \multicolumn{2}{c}{ Benign } & & \\
\cline { 2 - 6 } & No. & $\%$ & No. & $\%$ & No. & $\%$ \\
\hline Positive & 11 & 78.6 & 0 & 0.0 & 11 & 55.0 \\
Negative & 3 & 21.4 & 6 & 100.0 & 9 & 45.0 \\
\hline Total & 14 & 100.0 & 6 & 100.0 & 20 & 100.0 \\
\hline
\end{tabular}

The table shows that there were 14 patients with malignant tumors on histopathology, $78.6 \%$ out of them were true positive of ultrasound and $21.4 \%$ were false negative of ultrasound. There were 6 patients with benign tumor on histopathology, all of them were true negative on ultrasound. There was significant agreement between histopathology and ultrasound with Kappa value of 0.687 that indicate substantial agreement and $p$-value $<0.05$.

Table (8): Sensitivity, specificity, prediction values (positive $\&$ negative) and accuracy of pathological lymph nodes detected positive by ultrasound.

\begin{tabular}{lc}
\hline Diagnostic performance & Outcome\% \\
\hline Sensitivity & $78.6 \%$ \\
Specificity & $100.0 \%$ \\
Positive Predictive value & $100.0 \%$ \\
Negative Predictive value & $66.7 \%$ \\
Accuracy & $85.0 \%$ \\
\hline
\end{tabular}

Sensitivity (78.6\%), Specificity (100.0\%), Positive Predictive value (100.0\%), Negative Predictive value $(66.7 \%)$ and Accuracy $(85.0 \%)$. 
(A)

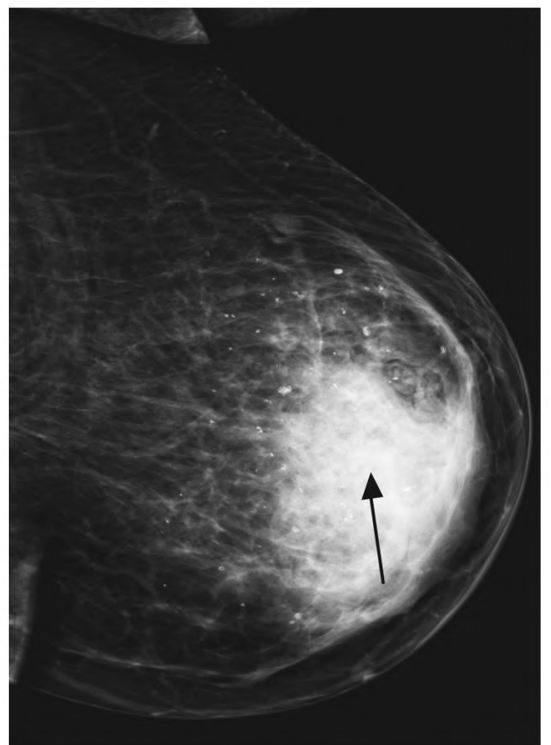

(C)
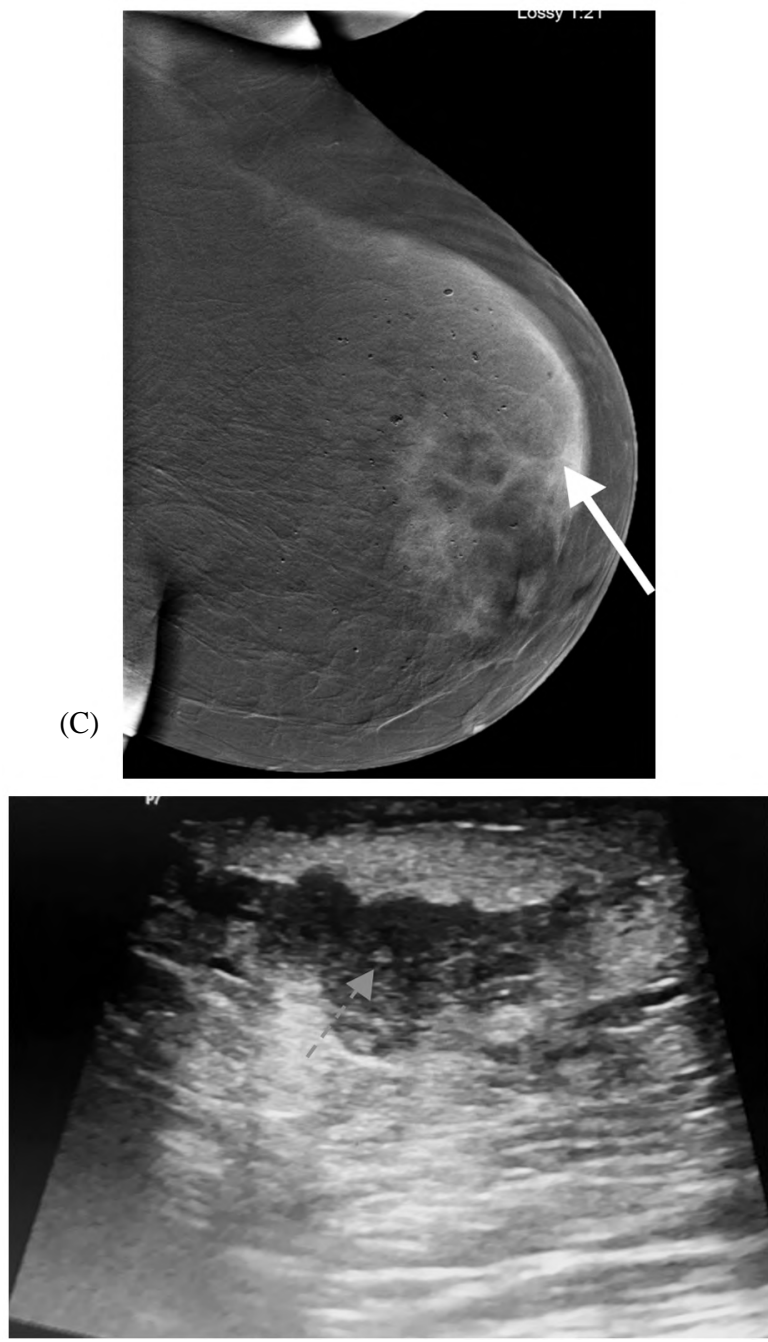

(B)

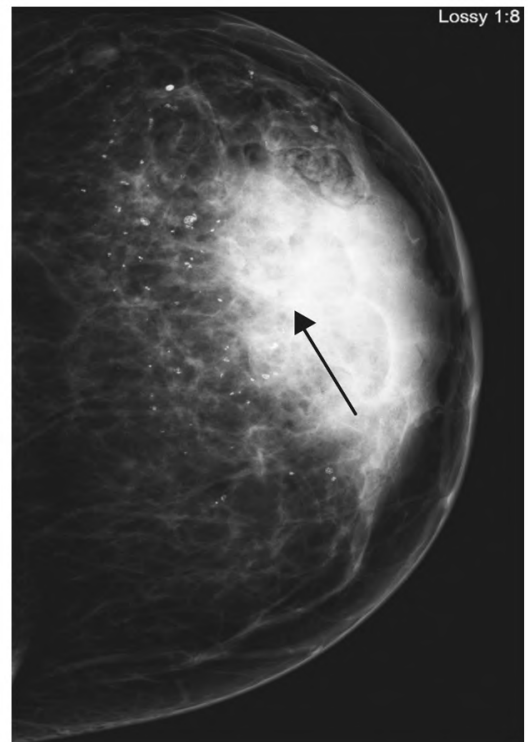

(D)
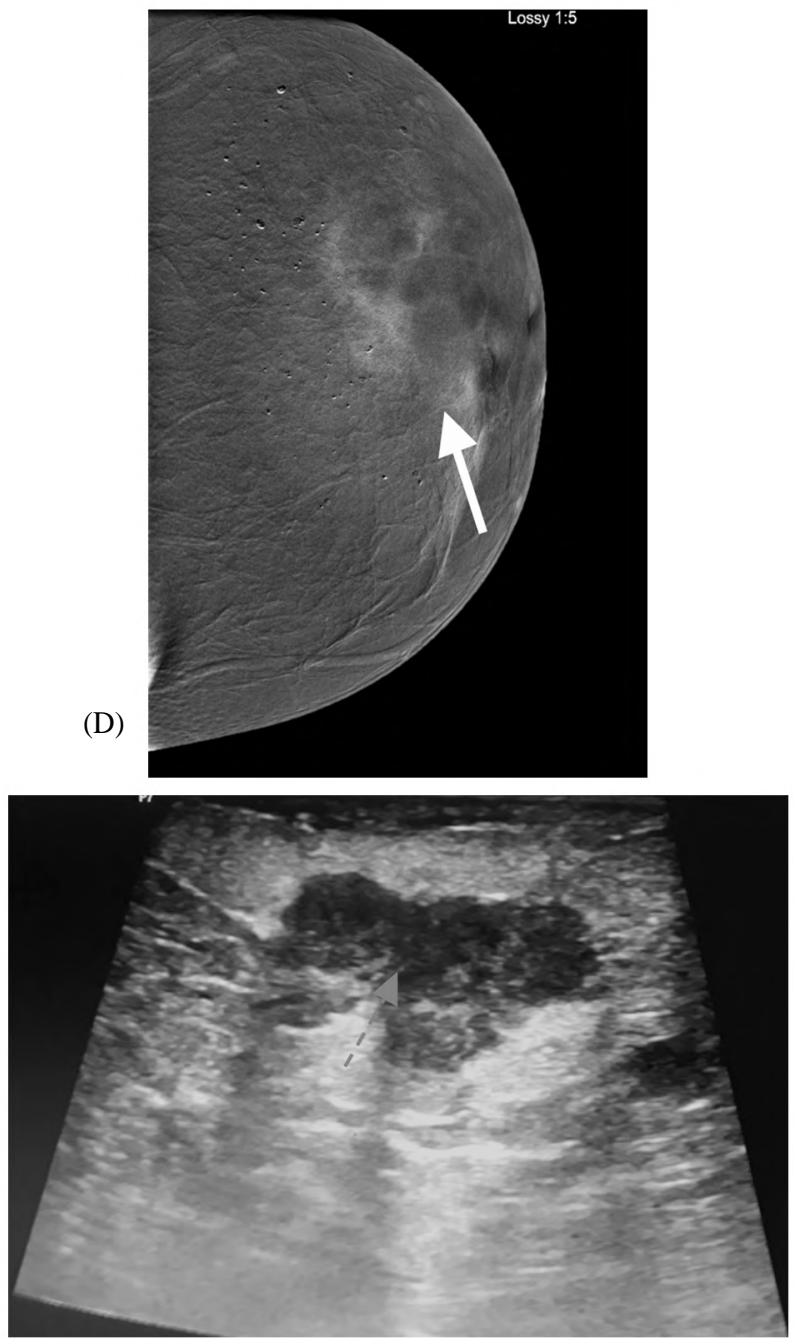

Fig. (1): 34-year-old female patient complaining of left breast edema and inflammation. (A,B): Mediolateral oblique and craniocaudal views of left breast showing mild edema with overall increased breast parenchymal density (black arrows) with multiple scattered calcifications. (C,D): Mediolateral oblique and cranicaudal views of contrast enhanced digital mammograohy of left breast showing large area of non-mass enhancement seen occupying central and retro areolar regions (white arrows). (E): Ultrasound examination of left breast multiple dilated ducts with inspissated secretion (red arrows) with no definite overlying internal vascularity

Histopathology: Revealed non caseating granulomatous mastitis. 


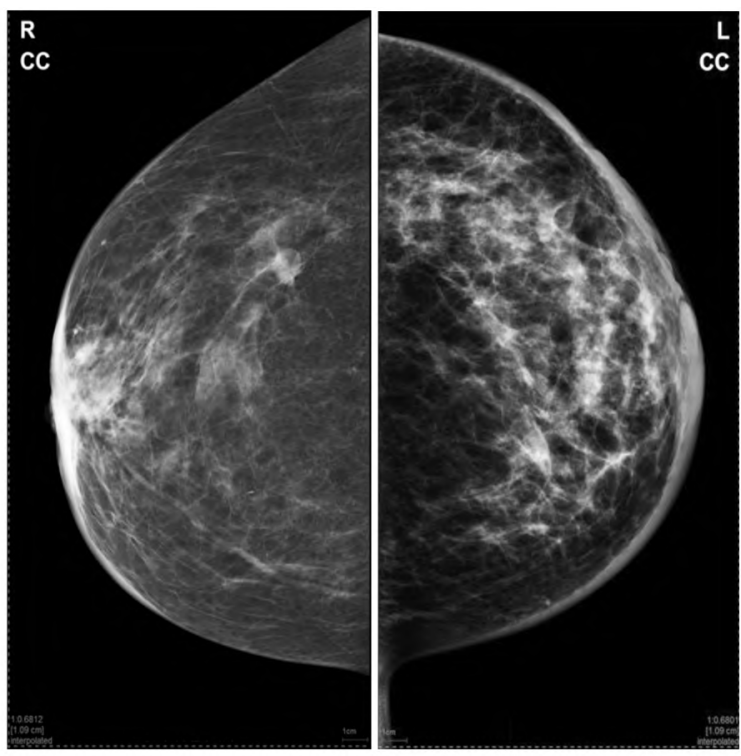

(A)

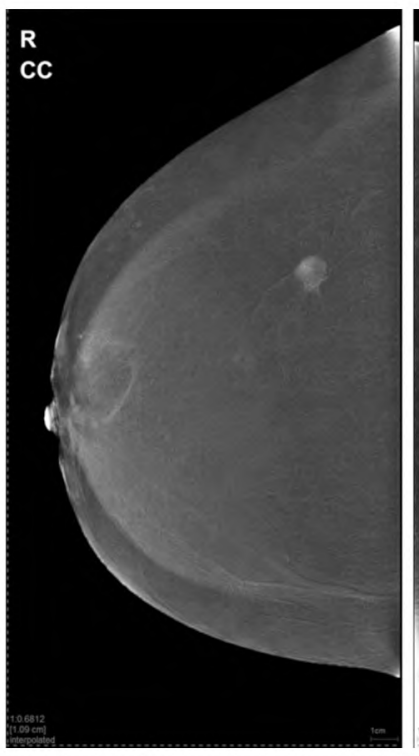

(C)

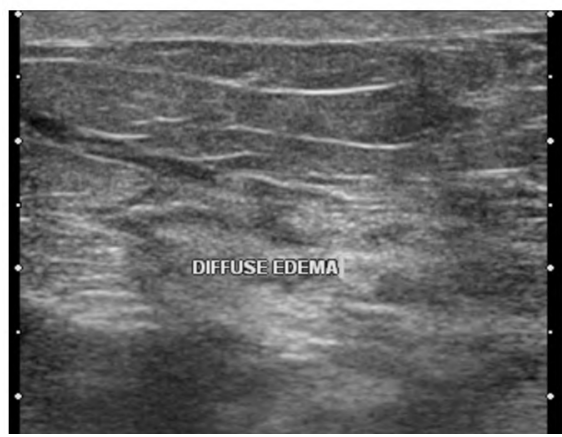

(E)
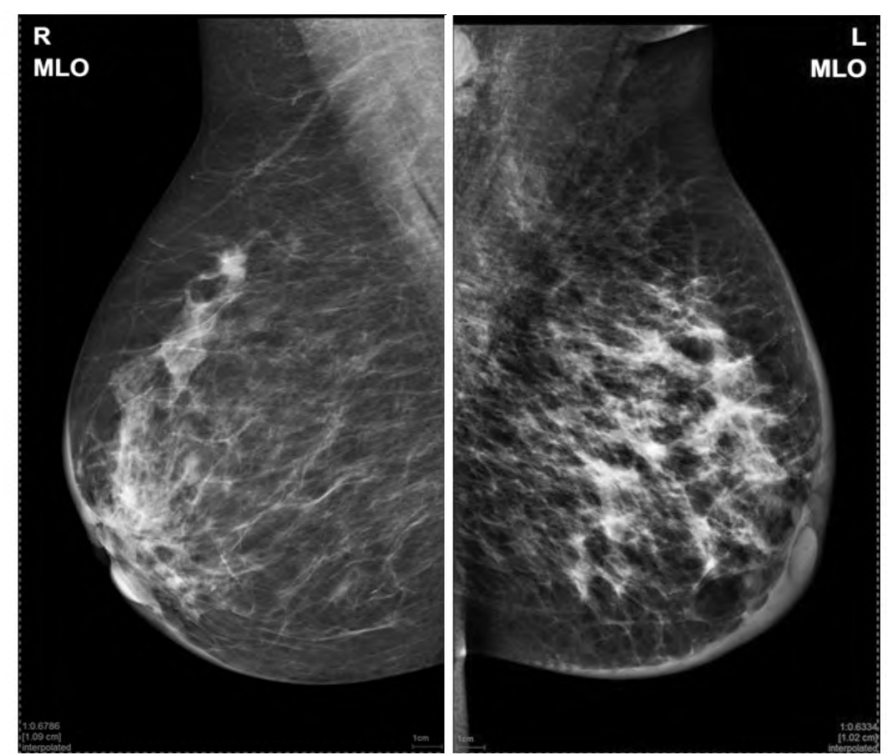

(B)
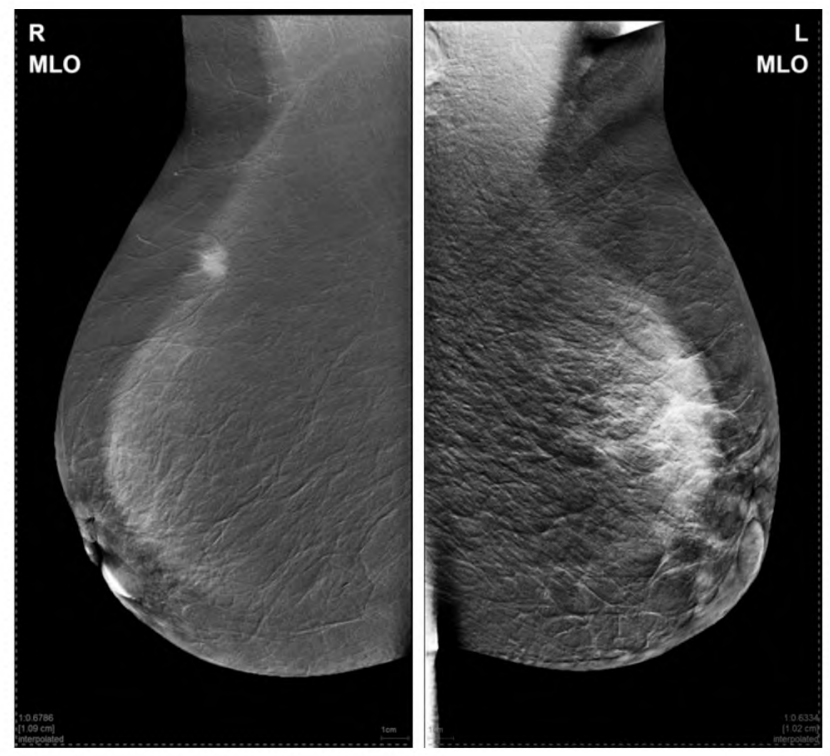

(D)

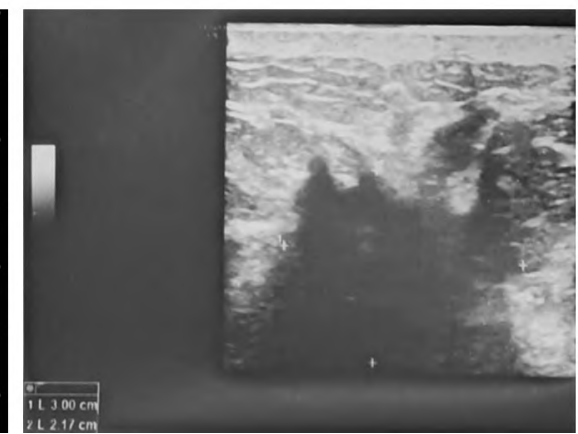

(F)

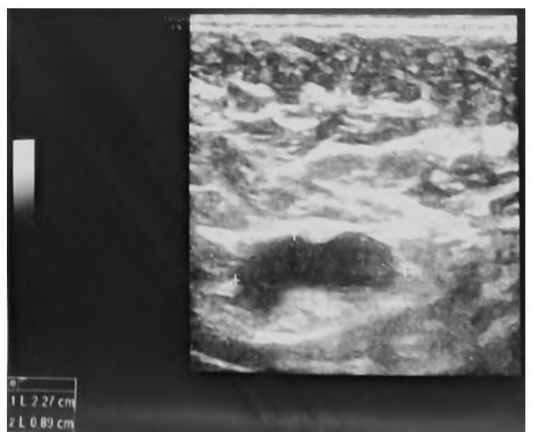

(G)

Fig. (2): Female patient 37 years old, complaining of bilateral breast heaviness. (A,B): Craniocaudal and mediolateral oblique views of both breasts showing edema pattern with left area of heterogenous central and UOQ density. (C,D): Craniocaudal and mediolateral oblique views of contrast enhanced digital mammography showing right well defined mass enhancement and left diffuse retroareolar enhancement. (E): Ultrasound of both breasts showed bilateral edema pattern, (F): Left hypoechoic mass lesion with $(\mathrm{G})$ : Ipsilateral pathological lymphnodes.

Histopathology revealed left Intraductal carcinoma and right atypical fibroadenoma. 


\section{Discussion}

Contrast-enhanced digital mammography is a new breast imaging technique that aims at demonstrating breast carcinoma angiogenesis. Technical and clinical experience has been acquired and encouraging results have been published during the last few years on CEDM as an adjunct to mammography [4].

In our study on breast ultrasound edema was positive in all patients (20 patients $100 \%$ ), pathological lymph nodes were detected in 11 patients $(55 \%)$. Bilateral in one patient $(9.1 \%)$, left sided in 5 patients $(45.5 \%)$ and right sided in 5 patients $(45.5 \%)$. In conventional mammography 19 patients (95\%) were positive for edema, while 11 patients $(55 \%)$ were positive for a mass (irregular) and one patient (5\%) was positive for calcifications.

In our study CEDM demonstrates contrast agent uptake in all the malignant lesions. Compared with mammography alone, CEDM significantly increased the sensitivity and the specificity. The sensitivity of CEDM was $92.9 \%$ vs. $71.4 \%$ and $78.6 \%$ for MX and US respectively, while specificity for CEDM was $83.3 \%$ vs. $83.3 \%$ and $66 \%$ for MX and US respectively.

CEDM also allowed a significant reduction in the false negatives. Fourteen patients with malignant tumors on histopathology, $92.9 \%$ out of them were true positive on contrast enhanced digital mammography and $7.1 \%$ was false negative on contrast enhanced digital mammography. While there were 6 patients with benign tumor on histopathology and $83.3 \%$ out of them were true negative on contrast enhanced digital mammography and $16.7 \%$ was false positive on contrast enhanced digital mammography. There was statistical significant agreement between histopathology and contrast enhanced digital mammography a yielded weighted Kappa value of 0.762 the indicate to substantial agreement and $p$-value $<0.05$.

This is also agreed with the study carried by Rizk et al., [5] using dual energy contrast enhanced mammography technique confirms the potential role for adding contrast enhanced dual energy mammography to improve the diagnosis of breast cancer the sensitivity was higher for MX+CEDM $(70.8 \%)$ than that was for ultrasound alone $(69.9 \%)$ or for mammography alone (52.9\%) compared to pathology with no loss in specificity [5]

This is also demonstrated by another dual energy CEDM study carried by Saad et al., include 60 patients with mammographically dense breast parenchyma, 14 patients had edematous breast changes. They noted that there was a significant increase in the detection of lesions and better assessment of the local extent of the disease in these patients with breast edema using CEDM. Of the 14 cases with edematous breast changes, CEDM placed 13 cases in the correct BI-RADS category versus 8 cases with MX alone. More lesions were detected by CEDM than by MX alone or by MX+US. The whole study concludes that Sensitivity was higher for CEDM than it was for MX+US ( $97.7 \%$ vs. $93.2 \%$ ), while specificity for CEDM was lower than it was for MX+US (50\% vs. $75 \%)$ [6]

This is agreed with the results of more extended temporal CEDM study by Diekmann et al., on 75 patients with 85 lesions compared the performance of conventional mammography alone versus temporal CEDM as an adjunct to conventional mammography. The results indicated an improvement in the sensitivity and specificity when adding temporal CEDM to the conventional mammography. However, several limitations affect temporal CEDM: The long examination and breast compression time contribute to patient discomfort and increases the probability of patient motion, generating artifacts on the subtracted images; moreover, only one view per breast can be acquired for a single injection of contrast medium. In addition to this, there has been no proof that the information provided by the contrast agent uptake kinetics is clinically useful. Also no correlation could be found between the contrast enhancement pattern and the malignant nature of the lesion. In Diekmann et al.'s study, it appeared that the diagnostically relevant information was mainly given by the morphology and intensity of the contrast agent uptake [7].

In current study CEDM gives relative important morphological informations as it found that 14 patients $(70 \%)$ showed enhancement ( +ve enhancement).

This is also supported with findings of another extended dual energy CEDM is done by Dromain $\mathrm{C}$, et al., to assess the diagnostic accuracy of CEDM as an adjunct to mammography versus mammography alone and versus mammography plus ultrasound on 120 women with 142 suspect findings on mammography and/or ultrasound underwent CEDM. There were 80 malignant, 50 benign and 3 pre-cancerous lesions (1 case of atypical hyperplasia and 2 cases of lobular carcinoma in situ). CEDM Enhancement was observed in 74 out of 80 malignant lesions. This study showed that sen- 
sitivity was higher for MX+CEDM than it was for MX (93\% vs. $78 \%$ ) with no loss in specificity. Moreover all 23 multifocal lesions were correctly detected by MX+CEDM vs. 16 and 15 lesions by MX and US respectively. Dromain C, et al., confirms that the Initial clinical results show that CEDM has better diagnostic accuracy than mammography alone and mammography plus ultrasound [8] .

Most of the previously published studies for CEDM, for example: Dromain et al., on 2011, Diekmann et al., on 2011 stated that the increase in sensitivity of cancer detection with CEDM is highly pronounced in dense breast parenchyma. Study performed Jong R et al., which performed temporal CEDM on 22 patients with suspected abnormalities found on conventional mammography or ultrasound. The results showed the ability of temporal CEDM to show cancers and suggested a potential to identify cancers in dense breasts [9]

The study carried by Dromain $\mathrm{C}$ et al., concluded from a 20-patient study that temporal CEDM has the potential to depict angiogenesis. The study was on patients with malignant findings only, detected contrast enhancement in $80 \%$ of the lesions [10].

As the metastatic axillary lymph nodes is an important frequent cause of breast edema. Ultrasound in our study revealed a higher detection and evaluation of axillary lymph nodes regarding sonographic evidence of malignant nodal invasion such as their morphological changes as well as preservation or effacement of their hyperechoic medulla.

Axillary lymphadenopathies are the single most important prognostic factor for operable breast cancer. Ultrasound is more accurate than both the physical examination and mammography in identifying metastatic axillary lymph nodes [11].

Benign lymph nodes usually present regular, oval or strip shape on the ultrasonic images, and hyperechoic medulla surrounded by the hypoechoic cortex. Longitudinal/transverse axis ratio (The L/T ratio) of the benign lymph nodes is usually above 2 . The $\mathrm{L} / \mathrm{T}$ ratio of the malignant ones is commonly below 2 . In most of the malignant lymph nodes, the medulla echo become narrow and sometimes disappears [12]

The diagnosis of residual and recurrent disease is often difficult because of post-surgical and postradiation changes. CEDM can be used in this cotnext [13]
In our study CEDM was helpful in differentiation of tumor recurrence and post-operative scar tissue as intense enhancement was observed in one of the 4 post-operative cases proved pathologically to be local recurrence while no contrast uptake was noticed in post-operative scar tissue in the other 3 cases.

The advantage of contrast-enhanced digital mammography should be less expensive and quicker compared to MRI [2].

On the other hand more recently, Sorin et al., [14]. Compared lowenergy images (obtained in the place of conventional 2D mammograms) with images obtained by performing the full CEM examination in women with intermediate breast cancer risk. Family or personal history of breast cancer was reported by $48.3 \%$ of patients, and $93.1 \%$ had a mammographic breast density of C or D. CEDM was found to have a sensitivity of $90.5 \%$.

Mammography demonstrated a sensitivity of $52.4 \%$ [14]. The authors determined that CEDM depicts cancer at an incremental rate of 13.1 cancers per 1000 women screened [14]. Unfortunately, CEDM was associated with more false-positive imaging findings than was conventional mammography. It resulted in multiple unnecessary biopsies in lesions proven to be benign at pathologic analysis. CEDM findings were inconclusive in 28 patients, who later underwent MRI [14].

Although limited, the available data suggest that CEDM may have a role in breast cancer screening More research is being performed to evaluate it for this indication [15]

\section{Conclusion:}

Addition of dual energy contrast enhanced digital mammography to conventional sonomammography can significantly improve the detection of underlying breast lesions in edematous breasts and determine the extent of disease.

\section{References}

1- Swart R.: Breast cancer. Breast cancer resource center, http://emedicine.medscape.com/article/283561-overview, 2010

2- DIEKMANN F., FREYER M., DIEKMANN S. and FALLENBERG E.M.: Evaluation of contrast-enhanced digital mammography. Eur. J. Radiol., 78: 112-21, 2011.

3- AN Y.Y., KIM S.H. and CHA E.S.: Diffuse infiltrative lesion of the breast: Clinical and radiologic features. Korean J. Radiol., 113-21, 2011.

4- DROMAIN C., THIBAULT F., DIEKMANN F., FALLENBERG E.M. and JONG R.A.: Dual-energy contrastenhanced digital mammography: Initial clinical results 
of a multireader, multicase study. Breast Cancer Res., 14: R94, 2012.

5- RIZK M.M.A., HELAL M.H. and ABDEL RAZEK N.M.: The Role of Dual Energy Contrast Mammography in Improvement of the Accuracy of Sonomammography in Evaluation of Breast Lesions. Cairo University, 20122013.

6- SAAD S.M., SELIM A. and MOKHTAR O.: The Role of Dual-energy Contrast-enhanced Digital Mammography in Detection and Diagnosis of Lesions in Dense Breasts. Cairo University, 2012-2013.

7- DIEKMANN F. and BICK U.: Tomosynthesis and contrastenhanced digitalmammography: Recent advances in digital mammography, Eur. Radiol., 17: 3086-309, 2007.

8- DROMAIN C., BALLEYGUIER C., MULLER S., MATHIEU M.C., ROCHARD F., OPOLON P. and SIGAL R.: Evaluation of tumor angiogenesis of breast carcinoma using contrast enhanced digital mammography. Am. J. Roentgenol., 187: W528-W537, 2006.

9- JONG R., YAFFE M. and SKARPATHIOTAKIS M.: Contrast-enhanced digital mammography: Initial clinical experience. Radiology, 228: 842-50, 2003.
10-DROMAIN C., THIBAULT F., MULLER S., RIMAREIX F. and DELALOGE S.: Dual-energy contrast-enhanced digital mammography. Eur. Radiol., 21: 565-574, 2011.

11- REGINI E., BAGNERA S., TOTA D., CAMPANINO P. and LUPARIA A.: Role of sonoelastography in characterizing breast nodules. Preliminary experience with 120 lesions. Radiol. Med., 115 (4): 551-562, 2010.

12- ZHANG Y., LV Q., YIN Y., XIE M. and XIANG F.: The value of ultrasound elastography in differential diagnosis of superficial lymph nodes. Front. Med. China, 3 (3): 368-374, 2009.

13- DROMAIN C., BALLEYGUIERA C., ADLERA G. and GARBAYB J.R.: Contrast-enhanced digital mammography. European Journal of Radiology, 69: 34-42, 2009.

14- SORIN V., YAGIL Y. and YOSEPOVICH A.: ContrastEnhanced Spectral Mammography in Women With Intermediate Breast Cancer Risk and Dense Breasts. AJR Am. J. Roentgenol., 211 (5): W267-W274, 2018.

15- U.S. National Library of Medicine. Clinical Trials. gov [database online]. Bethesda, M.D.: National Library of Medicine. https://clinicaltrials.gov/ct2/home . Accessed March 17, 2019.

\section{دور التباين المزدوج للطاقة المعززة

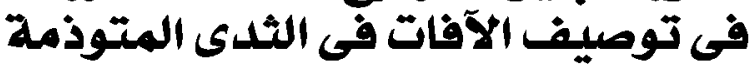

$$
\begin{aligned}
& \text { إن سرطان الثى هو أكثر أنواع السرطان شيوعاً لدى السيدات فى جميع أنحاء العالم، والسبب الرئيسى للوفاة بالسرطان لدى السيدات. } \\
& \text { تهدف هذه الدراسة: إلى تقييم دو التصوير بالأثعة الرقمية للثدى بالصبغة فى توصيف آفات الثدى المتورم. }
\end{aligned}
$$

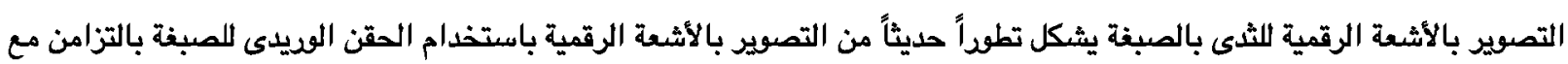

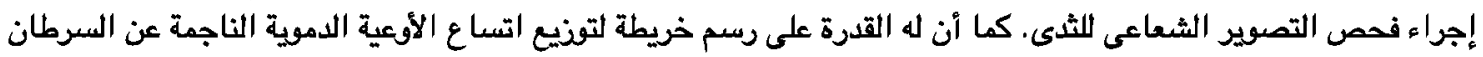

$$
\begin{aligned}
& \text { ويمكن أن يكن سبب توم الثدى عن طريق مجموعة متتوعة من الأمراض الحميدة أو الخبيثة. قد تحلث مع إلتهابات سرطان الثدى وعرقلة }
\end{aligned}
$$

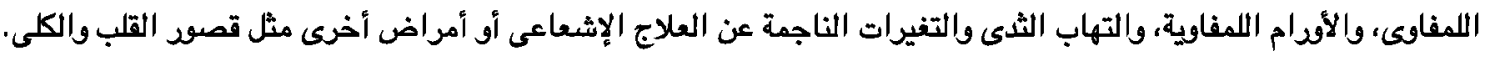

$$
\begin{aligned}
& \text { وقد أجريت تلك الدراسة على عشرين مريضة من مرضى توم الثىى بقسم الأثعة التشخيصية، جامعة عين شمس وتم تطبيق التصسوير }
\end{aligned}
$$

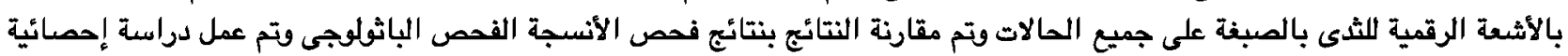

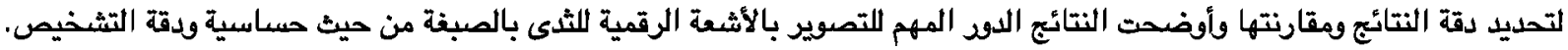

